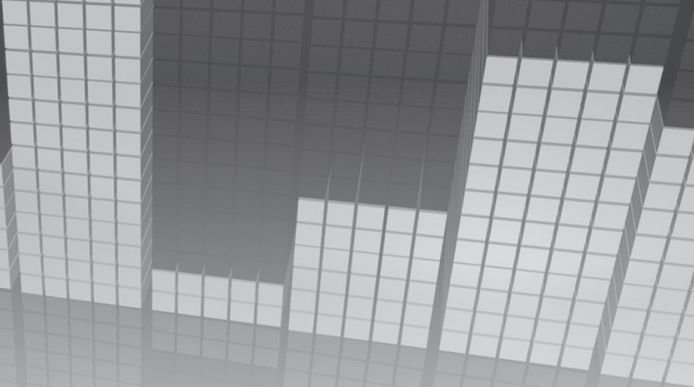

\title{
Derivatives and the real economy
}

Juraj Sipko

\section{Abstract}

The paper describes the development of the derivatives market and compares it with the development of the real economy. Based on official data the paper describes how the derivatives market has significantly increased its volume of trading, mainly after the abolishment of the Glass-Steagal Act. The growing volume of the derivatives market also significantly contributed to the global financial crisis. This paper also compares the growth of the global nominal and real gross domestic product with the pace of growth of the overall derivatives market, but mainly the over-the-counter market. Based on preliminary findings, the paper came to the conclusion that it is critical to implement all the requisite measures in order to eliminate non-transparent transactions with certain derivatives products in order to put the global economy on a sustainable, solid and balanced economic growth path.

Keywords: |credit default swap, derivatives, derivatives market, over-the counter market.

JEL classification: G1, G18, G 28 .

\section{Introduction}

The mortgage crisis in the USA brought about the global financial crisis. Academia, research and policy-makers still discuss who is responsible for the present financial turmoil. There is a general accepted agreement that the present global financial crisis is the result of complex issues ${ }^{11}$.

The comprehensiveness of this crisis is much deeper than of the Great Depression during the 30's in the last century. However, the present global financial crisis has one

1) The mortgage crisis in the USA is connected with the following negative factors, which have significantly contributed to the global financial crisis: expansionary monetary policy (2003 - 2005), underestimated risks in markets, failure of corporate governance, and failure of both supervision and regulatory of banking industry, failure of both rating and auditing companies and income distribution. In addition, strong support was providing by mass media, which have played a critical role in investing in real estate even in the time when participants of the market, research, academia, and policy-makers recognized the existence of the real estate bubble. 
specific phenomenon which significantly contributed to the global financial crisis financial engineering, i.e., financial derivatives ${ }^{2)}$.

The main aim of this paper is to create a clear picture of the development of the financial derivatives market, mainly at the beginning of the last decade of this century. Therefore, this paper will focus on history, the latest development of derivatives and a comparison of this development with the world real economic growth.

\section{History of derivatives}

Derivatives have a long history ${ }^{3)}$. However, historically trading with financial derivatives started at the beginning of the last century. The Bretton Woods international monetary system based on a fixed exchange rate collapsed on August 15, 1971. The breakdown of the fixed exchange rate system brought about a new international monetary system known as Kingston international monetary system.

The present Kingston international monetary system is based on demand and supplies of major currencies. Introduction of the floating exchange rate system caused instability of exchange rates of major currencies. These create a big space for trading with currencies and interest rates.

Since the breakdown of Bretton Woods system, there has been a significant increase in the trading volume of derivatives, i.e., both financial and commodities derivatives. The size of growth derivatives has had an unprecedented trend, mainly during the last decade.

Ever since this period derivatives are bought and sold in two ways. Contracts with standardized terms are traded on exchanges. Tailored varieties are bought "over the counter” (OTC) from big “dealer” banks. These banks support the OTC market by hedging their clients' risks with each other or on an exchange.

Based on available literature, both financial and commodities derivatives have existed for many centuries. Historically, there are two periods, when we registered a significant increase of volume of derivatives.

The first period was after the shutdown of the Bretton Woods system. According to the official data published by the Bank for International Settlements (BIS) from the beginning of 70's in the last century the volume of financial derivatives has significantly increased ${ }^{4}$.

2) Derivatives is the collective name used for a broad class of financial instruments that derive their value from other financial instruments (known as the underlyings), events or conditions. So, derivatives are financial instruments whose characteristics and value depend upon the characteristics and value of an underlier, typically a commodity, bond, equity or currency. Examples of derivatives include futures and options. Advanced investors sometimes purchase or sell derivatives to manage the risk associated with the underlying security, to protect against fluctuations in value, or to profit from periods of inactivity or decline. These techniques can be quite complicated and quite risky.

3) History of using derivatives started in the 17th century with traded futures. For example, the Japanese traded simple rice futures in Osaka and the Dutch bought and sold tulip derivatives in Amsterdam.

4) After the breakdown of Bretton Wood System (August 15, 1971) the volume of financial derivatives was approximately USD 75-78 billion. 
The second period was after the elimination of the Glass-Steagal Act ${ }^{5}$. During the period of existence of this Act a relatively low volume of derivatives was traded in comparison with the last decade. However, due to strong lobbing from the (financial industry), Wall Street was interested in abandoning this legislation. Finally, at the end of the second term of Mr. Clinton's presidency, was finally successfully cancelled the Glass-Steagal $\mathrm{Act}^{6)}$.

\section{Development of derivatives after the cancelation of Glass-Steagal Act}

Table 1

\begin{tabular}{|l|c|c|c|}
\hline \multicolumn{5}{|c|}{ The World of Derivatives } \\
\hline Type of Derivative & H1 2008 & End 2007 & H1 2001 \\
\hline Interest Rate & $\$ 464.7$ trillion & $\$ 382.3$ trillion & $\$ 57.305$ trillion \\
\hline Credit & $\$ 54.6$ trillion & $\$ 62.2$ trillion & $\$ 631.497$ billion \\
\hline Equity & $\$ 11.9$ trillion & $\$ 10$ trillion & \\
\hline
\end{tabular}

Source: BIS data, author's calculations.

Since this period the volume of derivatives has enormously increased (see Table 1 above). The table describes three types of derivatives (credit, interest rate, and equity) for three periods (first half of 2001, end 2007 and first half of 2008). On the one hand, the table clearly describes a big movement in different types of derivatives e.g., interest rates since the first half of 2001 to the end of 2008 from $\$ 57.305$ trillion in the first half of 2001 to $\$ 464.7$ trillion at the end of 2008 .

On the other hand, credit derivatives significantly reduced in volume from $\$ 631.497$ trillion in the first half of 2001 to $\$ 54.6$ trillion in at the end of 2008 . Paradoxically, the volume of derivatives had significantly increased between 2007 and at the end of 2008. This was a period when there was an evident lack of liquidity in the banking industry and Freddy Mac and Fenny Mae came under big pressure in terms of market value of mortgages of both of these institutions. This was a first-time development and many market it as a moral hazard, because the majority of CEOs stimulate further investment operations through various new derivatives products.

In addition, after canceling the historical Glass-Steagal Act there has been tremendous change in terms of growth of GDP and the volume of financial derivatives as is discussed subsequently.

5) In order to avoid potential financial crisis, the newly elected president of the USA appointed both Mesrs. Glass and Steagal to prepare a new legislation. The main goal of this legislation was separation of investment and commercial banking, introducing transparent operations and to solve the conflict of interest.

The New Act was adopted and was named after both social democrats in June 1933.

6) Elimination of the Glass-Steagal Act in November 12, 1999 (actually it was after the presidential election) strongly supported by Mr. Robert Rubin, Secretary of Treasury (the former Chief Executive in Goldman Sachs) and his Undersecretary Larry Summers (the former chairman of advisors to the present president Mr. Barak Hussein Obama) and by the former Chairman of the Federal Reserve System Mr. Alan Greenspan. 


\subsection{Growth of derivatives}

In order to better understand the increase of both financial and commodities derivatives after the breakdown of the Bretton Woods system, it is necessary to analyze their structure.

Generally, derivatives are qualified as follows: credit derivatives, over-the-counter derivatives, interest rate derivatives, credit default swaps, foreign exchange derivatives, commodity derivatives and equity-linked derivatives.

Graph 1 below describes the size of all derivatives before the outbreak of the global financial crisis.

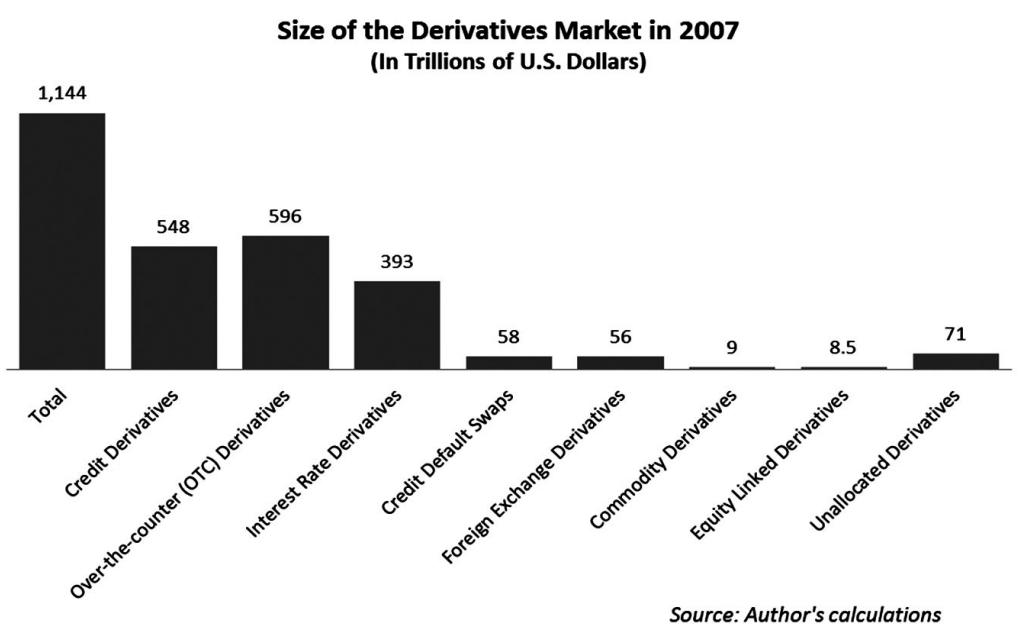

\section{Graph 1}

Source: BIS data.

At the end of 2007, the total volume of the derivatives market accounted for USD 1,147 trillion. The biggest size of derivatives market was over-the-counter derivatives $^{7)}$ which accounted for USD 596 trillion, then listed credit derivatives USD 548 trillion, interest rate derivatives USD 333 trillion, credit default swaps USD 58 trillion, foreign exchange derivatives USD 56 trillion and only USD 9 trillion was counted for commodities and USD 8.54 trillion for equity-linked derivatives.

According to the Bank for International Settlements unallocated derivatives at the end of 2007 were at about USD 71 trillion. The graph clearly shows that a dominant position in the derivatives market belongs to OTC derivatives.

\subsection{Financial and commodities derivatives}

The value of financial and commodity derivatives depend on the underlying value of the basic securities. However, both financial and commodities derivatives are associated with potential risk. The total volume of the derivatives has significantly increased during the last decade.

7) The OTC market is the biggest market with financial and commodities derivatives. The global gross domestic product at the end of 2007 was USD 50 trillion. The total volume of derivatives market accounts for USD 1,144 trillion. This means that it is 22 times higher than GDP of the whole world. The market value of real estate is counted at around USD 75 trillion. The world stock and bond market value is about USD 100 trillion. 
There is general agreement between researcher, academia and policymaker that derivatives are unregulated, non-traded at any public exchange without universal standard. In reality, it means that some derivatives are not transparent and do not have an open bid/ask market; obviously, they are not guaranteed and they have no clearing house.

Clearly, financial derivatives are related to futures and options which are traded on exchanges. However, there are a lot of over-the-counter instruments such as interest rate swaps, foreign contracts and foreign exchange and interest rate contracts. In addition, there are various commodity and equity instruments.

Nowadays, derivatives are commonly used by both financial and non-financial institutions as well as large and small speculators. In comparison with the beginning when derivatives started to operate, the present development trend of trading over-the-counter (OTC) derivatives is on upward trend.

Over-the-counter market derivatives, as it was mentioned before, have the biggest size of all derivatives in the derivatives market.

\section{The volume of financial derivatives and real GDP growth}

Although the latest development of derivatives is significant, so far there haven't been many articles comparing the growth of derivatives and the growth of the real economy. Therefore, it is important to compare the growth of derivatives with the growth of the real economy to be able to explain the increased systemic risk of the financial system.

Based on official data published by the International Bank for Settlement, total derivatives have been significantly growing since the abolishment of the Glass-Steagal Act (see Graph 1 above).

The development of economic growth both nominal and real is described since 1960 in Graph 2 below. This graph clearly shows that economic growth was on an upward trend, but increasing mildly during the last 50 years. The development of both nominal and real economic growth was in strong correlation. Nominal economic growth before the outbreak of the global financial crisis (2007) reached USD 62,173 trillion.

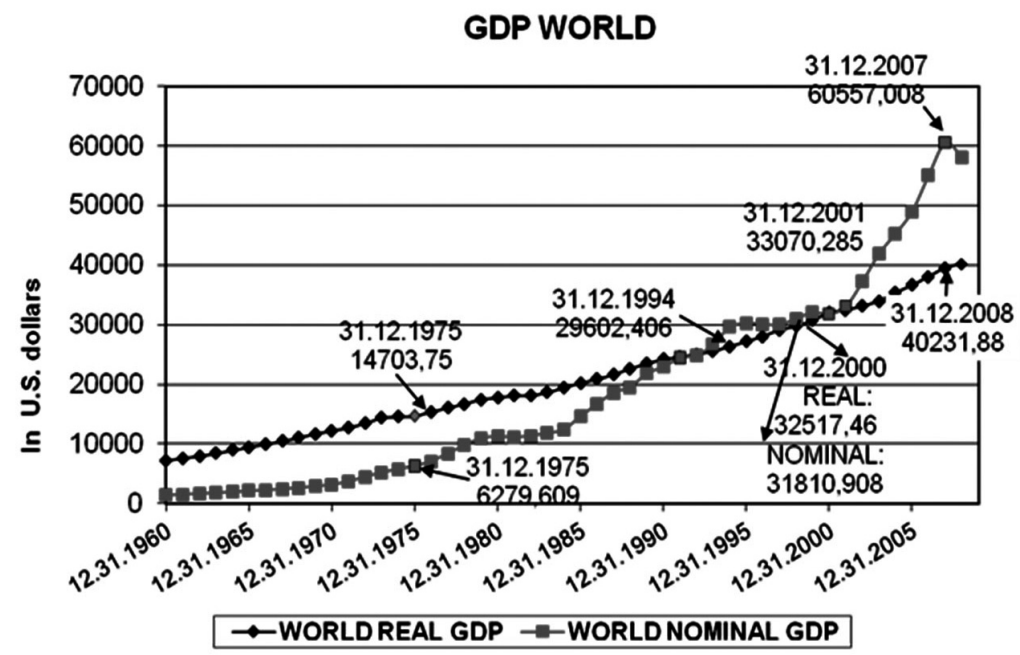

Source: BIS data, author's calculations. 
A completely different situation arises when comparing derivatives with interest rates. After the breakdown of the Bretton Wood system there has been a gradual increase in currency and interest rates.

Graph 3 shows that interest rate derivatives started to grow since the second half of the 90's. However, extraordinarily fast growth of interest rate derivatives continued since the abolishment of the Glass-Steagal Act. The steep curve clearly shows a huge increase of derivatives from USD 50 trillion in 2000 to USD 426,749 trillion in 2009.

\section{GDP WORLD}

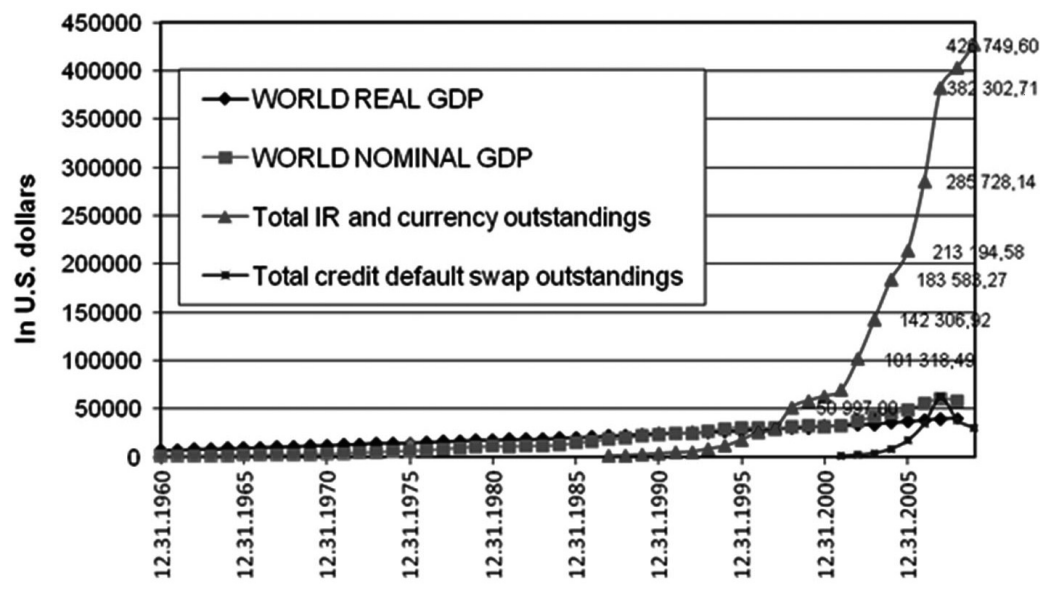

Graph 3

Source: BIS data, author's calculations.

One of the most critically important financial derivatives which have significantly contributed to the global financial crisis was credit default swaps ${ }^{8)}$. This type of financial derivative was introduced at almost the same period of time as the abolishment of the Glass-Steagal Act. The volume of credit default swaps was USD 62,173 trillion at the end of 2007.

In reality, credit default swaps at the end of 2007 have the same volume as the global gross national product. That means that this kind of derivatives, which are non-transparent, reached the same volume as the annual global gross domestic product. However, since the end of 2007, there was a decline of credit default swaps and at the end of 2009 reached a volume of USD 30,428 trillion.

8) Credit default swap or CDS trading is closely related to trading in the underlying securities that compose the capital structure of the companies on which protection is written. Trading practices in the CDS market, whether legitimate or abusive, can affect the securities markets. The CDS market, however, lacks the level of transparency and other protections that characterize the regulated securities markets.

Therefore, the Secutity Exchange Commission (SEC) in the USA has been unable to monitor effectively for trading abuses and whether purchasers of CDS protection on an issuer's debt have sold short the equity securities of that company as a trading strategy, effectively linking activities and changes in the CDS market with those in the cash equity market.

These activities in the CDS market could adversely impact the regulated securities markets. Any regulatory reform that maintained distinct regulatory regimes for securities markets and markets for securities-related OTC derivatives would suffer from this same limitation. 


\subsection{The dynamics of financial derivatives}

In order to better understand the entire volume of all derivatives, i.e., both financial and commodity derivatives, it is necessary to understand the main structure. At the end of 2007, the overall volume of derivatives was USD 1,144 trillion.

Graph 4 below describes the OTC derivatives market since December 2007 to December 2009. The total volume of the derivatives market the end of 2007 accounts for USD 596 trillion. Since December 2007 until December 2008, there was a huge increase in the OTC market; i.e., to USD 683 trillion. Therefore, within 12 months, there was an increase of USD 88 trillion. When the global financial crisis spilled over across the globe, a decrease in OTC derivatives was recorded. However, since the beginning of 2009, gradually, the volume has been increasing all throughout 2009 .

Finally, at the end of 2009, the volume of the OTC derivatives market was USD 614 trillion, which is even bigger volume than it was before the crisis started.

\section{Notional Amounts Outstanding of OTC Derivatives \\ (In Billions of U.S. Dollars)}

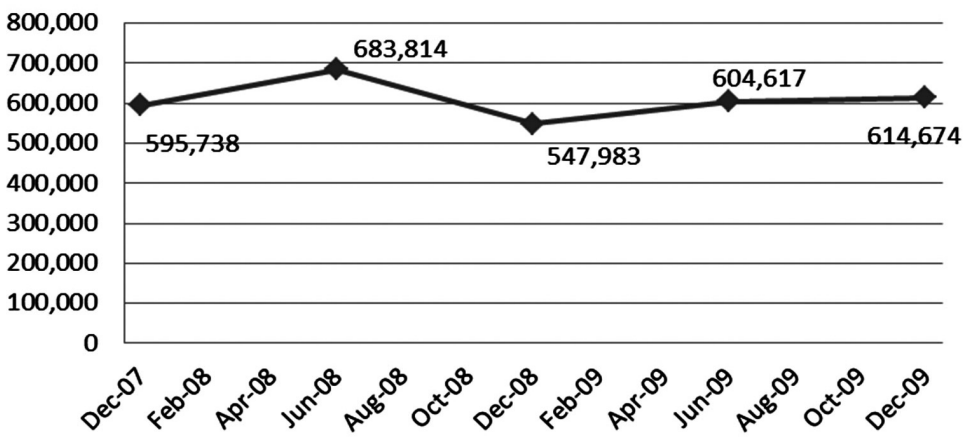

\section{Graph 4}

Source: BIS data, author's calculations.

Graph 5 below provides a further breakdown of notional amounts outstanding of OTC derivatives.

In order to better understand the real economic growth for the last 50 years, it is necessary to compare nominal and real world GDP. According to Chart 3, there is a historical development of both world nominal and world real GDP. The development of both nominal and real GDP is correlated since the beginning of the 60s until the beginning of the last decade. At the end of 2000, world nominal GDP counted for USD 31.8 trillion. For the same period of time, world real GDP was counted for USD 32.5 trillion. However, since the beginning of 2001, there has been a significant growth in world nominal GDP. One explanation of this might be that the world nominal GDP is growing faster due to the huge increase of derivatives markets. Nonetheless, the increasing size of derivatives markets is not part of the real economy. ${ }^{9)}$

9) As was mentioned before, the abolishment of the Glass-Steagal Act created unparalleled conditions for fast-growing derivatives markets, including those which are less or non-transparent. The notional amount of OTC derivatives outstanding globally at the end of 2000 was approximately USD 95 trillion. Between the end of 2000 and the end of 2008, the volume of outstanding OTC derivatives outstanding was increased more than 7 -fold to the total volume of USD 672 trillion. 
In reality, based on comparison between the global real economic growth and the OTC derivatives market in terms of volume, it brings us to the conclusion that the global derivatives market is growing much faster than the global real GDP. Although there is no clear distinction about how big the volume of this speculation is, one thing is clear, nowadays, derivatives have started to dominate instead of the real economy.

\section{Notional Amounts Outstanding of Over-the-counter (OTC) Derivatives \\ (In Billions of U.S. Dollars)}

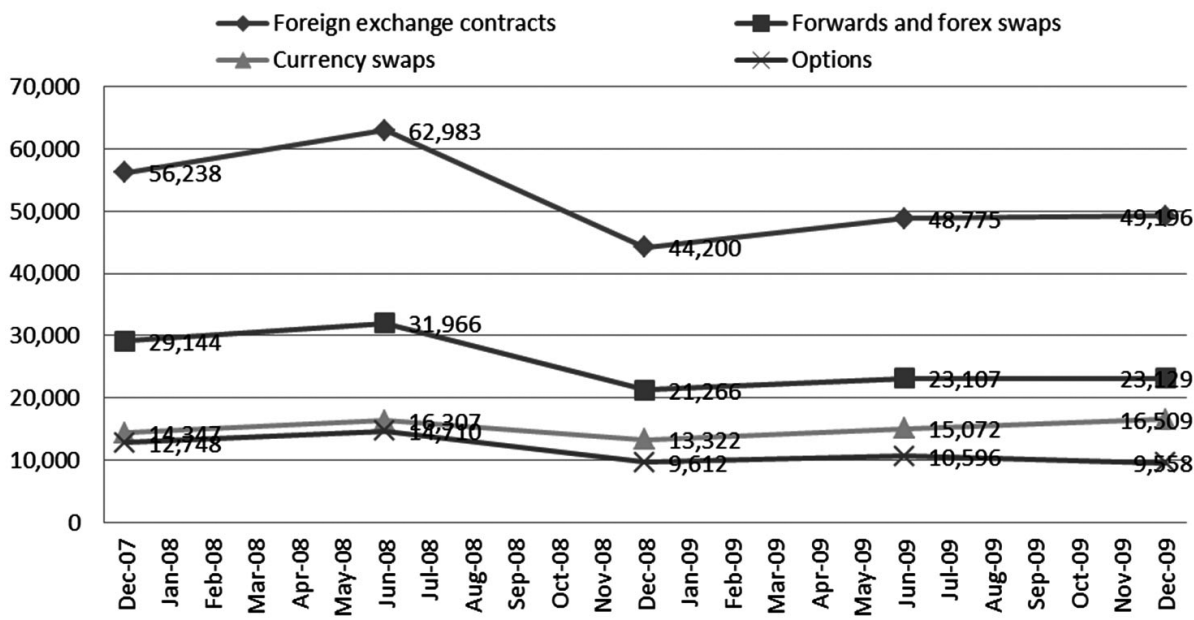

Graph 5

Source: BIS data, author's calculations.

Some types of derivatives played a dominant role in OTC derivatives markets. Among those both interest rate contracts and interest rate swaps are predominantly in notional amounts outstanding OTC derivatives. Graph 5 above shows how big a proportion there is of both types of derivatives to the total size of OTC derivatives. On one hand, some kinds of derivatives such as options and OTC derivatives are of relatively low volume to the total notional amount of outstanding OTC derivatives. On the other hand, option derivatives during the period of 2007 and 2009 recorded a downward trend. Both derivatives for interest rate contracts and interest rate swaps after their decrease during the global financial turmoil started growing linearly with growth after the crisis.

Due to the role which the derivatives market has played in the emerging of the global financial crisis, the G 20 was led to reevaluate the present legal framework and transparency of the existing derivatives markets. Therefore, after the outbreak of the global financial crisis member countries of Group 20 decided to prepare an agenda for avoiding a potential financial crisis in the future.

\section{G-20 and regulatory framework for derivatives market}

Research, academia and policymaker, after analyzing the main causes of the global financial crisis, came to the conclusion that the derivatives market significantly contributed to the global financial turmoil. Therefore, G-20, in order to avoid potential 
crises, discussed regulatory framework for the financial sector, including the derivatives market.

The main goal of the financial sector reform in terms of derivatives market is follow the four broad-based objectives: 1) preventing activities in OTC derivatives from posing risk to the global financial system, 2) promoting efficiency and transparency of those markets, 3) preventing market manipulation, fraud and other market abuses and finally, 4) ensuring that OTC derivatives are not marketed inappropriately to unsophisticated parties.

Based on these four objectives, the most important will be primary responsibility for the OTC derivatives market. In the United States, this primary responsibility for all OTC derivatives including derivatives related to exchange rate, interest rate, commodities energy and metal, would rest under an umbrella of CFTC (Commodities and Financial Trade Commission) ${ }^{10)}$.

G-20 adopted an agenda for improving the legal framework for the derivatives market. The main goal of this agenda is to specify the relation between securities markets and security-related OTC derivatives. Based on this agenda, the regulatory framework for OTC derivatives is very important to recognize the relationship between regulated securities market and the unregulated markets for securities related to OTC derivatives. ${ }^{11)}$ Currently, the legislation is under discussion. Still there are some open issues between the USA and EU.

\section{Conclusion}

Financial derivatives have significantly contributed to the mortgage crisis in the USA and the later spillover to the global financial crisis. Although there are some similarities of the present financial crisis with the Great Depression, the one specific feature of the present global financial crisis is that it was strongly influenced by financial derivatives. There is clear evidence that some of the financial derivatives such as credit default swaps were not, or less transparent.

The elimination of the Glass-Steagal Act was a step in the wrong direction. An unprecedented increase of the financial derivatives led to worsening of the financial position in the banking industry in both commercial and investment banks.

Despite the fact that the competent international monetary and financial institutions recognized that regulatory and supervisory bodies failed to deal with the transparent management of the financial derivatives so far this agenda is pending. So far the overall agenda is under preparation and there is expectation that will come to force in 2013.

Before the Great Depression the financial derivatives did not play a critical role in the financial crisis. The present problem is the unprecedented development in terms of

10) According to SEC (Security Exchange Commission), some securities products are very actively traded. For example, the most traded financial product in the world with exchange-listed US equities are trading approximately 11 bn shares per day. In the US, there are 11 national securities exchanges. The national securities exchanges have self-regulatory responsibility with more than 70 alternative trading systems for executing OTC transactions. In addition, there are hundreds brokers and dealers that are actively participating in OTC transactions.

11) According to G-20 agenda, there is an expectation that the regulatory framework for the derivatives market will be implemented since 2013. 
volume of financial derivatives in comparison with real GDP growth. From the analysis by using official data published by the International Bank for Settlements it brings to the conclusion that derivatives market is growing much faster than the real economy.

The real question is whether this trend is sustainable from the long term perspective. Analysis clearly demonstrates that significant growth of the derivatives market, mainly markets with less or non-transparent products might undermine the stability the whole financial sector. In addition, a fast growing volume of transactions in the derivatives market does not create favorable conditions for supporting the still uneven and fragile global economic growth, but in particularly in industrial countries, those were this market is dominating.

To put the global economy on a solid, balanced and sustainable path an appropriate regulation on derivatives, in particular on markets, which are less, or non-transparent is needed.

Without adoption of all the necessary measures to regulate derivatives in a non-transparent market it will be difficult to stabilize the real economic growth for medium and long term perspectives. Therefore, rigorous efforts on the international level connected with fruitful cooperation in improving the functioning of the derivatives market is critical. In addition, these efforts should be consistent between all major players in the derivatives market, i.e., in the USA and in Europe.

The only way to accomplish this task is adopt the correct rules of game which will support transparency in the derivatives market and support, but not undermine, the still fragile real economic growth, which is imperative to increase the standard of living of all populations around the globe.

\section{References}

Acharya, V V and L H Pedersen (2005): “Asset pricing with liquidity risk”, Journal of Financial Economics, vol 77, no 2, pp 375-410.

Acharya, V V and S Viswanathan (2008): Moral hazard, collateral and liquidity, CEPR Discussion Papers 6630, Centre for Economic Policy Research.

Bank for International Settlements, Annual Report (2000-2011).

Borio, C E V and H Zhu (2009): “Capital regulation, risk-taking and monetary policy: a missing link in the transmission mechanism?” BIS Working Papers, no 268, Basel.

Castren, O, S Dees and F Zaher (2008): "Global macro-financial shocks and expected default frequencies in the euro area”, European Central Bank Working Paper Series, no 875.

Dees, S and I Vansteenkiste (2007): “The transmission of US cyclical developments to the rest of the world”, European Central Bank Working Paper Series, no 798.

De Graeve, F, T Kick and M Koetter (2008): "Monetary policy and financial (in) stability: an integrated micro-macro approach”, Journal of Financial Stability, vol 4, no 3, pp 205-31.

Estrella, A and G Hardouvelis (1991): "The term structure as a predictor of real economic activity”, Journal of Finance, vol 46, pp 555-76.

Fisher, I (1933): “The debt-deflation theory of great depressions”, Econometrica, vol 1, no 4, pp 337-57.

Gilchrist, S, V Yankov and E Zakrajšek (2009): "Credit market shocks and economic fluctuations: evidence from corporate bond and stock markets”, Journal of Monetary Economics, vol 56, no 4, pp 471-93.

G20 Communique (2008-2010). 
Gorton, G (2008): “The Panic of 2007”, NBER Working Papers, no 14358.

Harvey, C R (1991): “The term structure and world economic growth”, The Journal of Fixed Income, vol 1, pp 7-19.

International Monetary Fund, Global Financial Stability (2006-2010).

Joint Working Group of the Financial Stability Forum and the Committee on the Global Financial System (2009): "The role of valuation and leverage in procyclicality", CGFS Papers, no 34.

McCarthy, J and R W Peach (2004): “Are home prices the next 'bubble'?”, Federal Reserve Bank of New York Economic Policy Review, vol 10, no 3, pp 1-17.

Qi, M and X Yang (2009): “Loss given default of high loan-to-value residential mortgages”, Journal of Banking and Finance, vol 33, no 5, pp 788-99.

Segoviano, M (2006): “Conditional Probability of Default Methodology”, Financial Markets Group Discussion Paper 558. London School of Economics.

Strahan, P (2008): "Liquidity production in 21st century banking”, NBER Working Papers, no 13798.

Zhu, H (2008): “Capital regulation and banks’ financial decisions”, International Journal of Central Banking, vol 4, no 1, pp 165-211.

\section{Ass. Prof. Juraj Sipko, PhD.,}

Paneuropean University, Faculty Economy and Business,

Tematinská 10, 85105 Bratislava, phone: 02/68203615,E-mail: juraj.sipko@uninova.sk 